\title{
VALORACIÓN Y GESTIÓN INTEGRAL DEL PATRIMONIO PAISAJISTIICO. ENCUENTROS Y DESENCUENTROS TEÓRICOS Y PRÁCTICOS ${ }^{(*)}$
}

\author{
VALUATION AND HOLISTIC MANAGEMENT OF LANDSCAPE HERITAGE. THEORETICAL AND \\ PRACTICAL AGREEMENTS AND DISAGREEMENTS \\ IVÁN RAMÍREZ SERPA ${ }^{(*)}$
}

Fecha de recepción: 10 de diciembre de 2016

Fecha de aprobación: 01 de noviembre de 2017

\section{RESUMEN}

El presente artículo pretende ser un texto reflexivo, el cual, desde un enfoque analítico, crítico y práctico de la noción de territorio y paisaje cultural, exprese como esta dualidad conforma la concepción del patrimonio de manera holística, con el objetivo de demostrar que el componente patrimonial es determinante e ineludible para la ordenación del territorio, la planificación urbana y el desarrollo sostenible. Mediante la exploración de definiciones teóricas, acuerdos internacionales, propuestas de gestión y ejemplos de casos prácticos en el Perú, se encuentra la correlación e implicancia entre la teoría y la práctica, y la integralidad del componente patrimonial. La reflexión parte del enunciado de Ramón Folch de que "el paisaje es el aspecto del territorio y compendia la historia del proceso antrópico que en él se ha podido desarrollar". De esta manera, se interpreta que el paisaje cultural trasmite y refleja el modelo de desarrollo instaurado en un determinado territorio, y su efecto sobre el patrimonio.

\section{PALABRAS CLAVE}

Territorio, valoración del paisaje cultural, gestión del patrimonio, parque patrimonial

\section{ABSTRACT}

This article aims to be a reflective text, and to express, from an analytical, critical and practical approach to the notion of territory and cultural landscape, how said duality shapes the conception of heritage in a holistic way. Its goal is to show the decisiveness and inescapability the patrimonial component has for the purpose of the planning of territory, urban planning and sustainable development. The correlation and implication between theory and practice, and the comprehensiveness of the patrimonial component, are found through the examination of theoretical definitions, international agreements, management proposals and examples of practical cases in Peru. The reflection is set off by Ramón Folch's statement, that "the landscape is the aspect of the territory and summarizes the history of the anthropic process that it has been able to develop". In such a way, the article interprets that the cultural landscape transmits and reflects the model of development established in a given territory, and its effect on heritage.

\section{KEYWORDS}

Territory, cultural landscape assessment, heritage management, patrimonial parks

\footnotetext{
(*) El presente artículo fue desarrollado a partir del texto Breves Alcances a la Transformación y Valoración del Territorio, Medio Ambiente y Paisaje en Relación al Caso del Perú, como parte del trabajo final de la asignatura Territorio Medio Ambiente y Paisaje, curso a cargo del profesor Carlos Verdaguer (Dirección: José Fariña Tojo y Ester Higueras), del máster de Planeamiento Urbano y Territorial - Itinerario de Estudios Urbanos (edición 20162017) de la Escuela Técnica Superior de Arquitectura, Departamento de Urbanística y Ordenación del Territorio, Universidad Politécnica de Madrid (UPM).

(**) Arquitecto por la Universidad Ricardo Palma (Lima, 2005). Cuenta con una maestría en Desarrollo Urbano y Ordenamiento Territorial por la Universidad Politécnica de Cataluña (2012-2013), y otra en Planeamiento Urbano y Territorial - Especialidad de Estudios Urbanos por la UPM (2016-2017). Laboró como jefe y coordinador de proyectos en la ONG Grupo GEA (Lima-Arequipa, 2006-2011), arquitecto en el equipo del Plan Metropolitano de Desarrollo Urbano de Lima y Callao al 2035 (Municipalidad de Lima, 2013-2014), y especialista en Movilidad Urbana Sostenible en la Subgerencia de Movilidad Urbana - Gerencia de Sostenibilidad (Municipalidad San Isidro, 2015-2016). Actualmente se desempeña como consultor para municipios y ministerios de Perú, y Organismos de Cooperación Internacional. Contacto: ivanrserpa@gmail.com
} 
El siguiente texto plantea la necesidad de reconocer la concepción del paisaje cultural como un concepto único: el patrimonio (Sabaté, 2005). Se trata de aquel paisaje que se interpreta como el reflejo del territorio (Folch, 2011), donde cualquier extracto de este, ya sea natural o intervenido por la sociedad humana, configura un paisaje, es decir, un concepto integrador de referentes físicos y funcionales en constante transformación, representativo de un determinado espacio y tiempo. Por ello, cualquier tipo de paisaje puede ser considerado como de especial particularidad, según la huella que sobre él haya dejado un determinado grupo social. Este es el contexto que se plantea para entender el paisaje en toda su dimensión patrimonial, el cual genera un vínculo ineludible entre las políticas de gestión territoriales, paisajísticas y patrimoniales (Mata, 2008).

Las referencias físicas y funcionales del paisaje comprenden una cantidad infinita de información, que puede ser clasificada en relación a la meteorología, edafología o geología, biología y antropología. Esta información sistemática reproduce valores estéticos (Ferraiolo, 1999; Scasozzi, 2002; Mata, 2008) que se reconocen en cada territorio, estrechamente ligados a la posibilidad de contemplar y leer en sus paisajes la complejidad de la historia del planeta Tierra. Si dichas referencias estéticas solo se concentran en su relación con el componente antropológico o sociológico (entendido como un fenómeno muy particular, por la capacidad acelerada de la sociedad humana de adaptar el territorio a sus necesidades), se puede aceptar, tal como plantea Venturi, "que es imposible separar los cambios sociales, la modificación de los modos de producción, de las formas urbanas, de los modos de vida, de la actividad laboral y económica, sobre todo de la visión del mundo y de la vida" (citado en Mata 2009, p. 6). De esa manera se genera un paisaje cultural, un registro de la humanidad sobre el territorio, "un texto que se puede escribir e interpretar, pero asimismo reescribir, entendiendo el territorio como construcción humana" (Sabaté, 2010, p. 11).

La intervención sobre este paisaje cultural lleva a formular nuevos modelos de gestión, como los llamados parques patrimoniales (Pérez \& Parra, 2004), gestados y muy difundidos en Estados Unidos y en Europa. Esta modalidad de gestión entiende el patrimonio paisajístico como un elemento que puede ser valorizado mediante una serie de estrategias de ordenamiento y desarrollo territorial. Esta valoración no se define sesgadamente en el sentido productivo y de mercado, ya que incluye toda la integralidad de cualidades del paisaje, en cuya virtud es apreciado (Ortega, 1999; Sanz, 2000; Mata, 2008).

La Comunidad Europea ha logrado importantes avances en la gestión del paisaje, como resultado de acuerdos políticos territoriales entre sus estados miembros, como la Estrategia Territorial Europea (ETE, 1999) y el Convenio Europeo del Paisaje (CEP, 2000). El primer documento, cuando se refiere a la "gestión creativa de los paisajes culturales", destaca que los paisajes culturales contribuyen "a través de su singularidad, a la identidad local y regional", y que su interés en su aprovechamiento económico va más allá de su mera conservación, pues "la conservación de estos paisajes es importante, pero no puede obstaculizar en exceso o incluso hacer imposible su explotación económica" (p. 36). En cuanto al CEP (2000), este se sitúa en una posición similar, pues considera al paisaje europeo como la "expresión de la diversidad de su patrimonio común cultural y natural y como fundamento de su identidad" (p. 3), además de un recurso económico creador de empleo, debido a su potencial turístico como aspecto importante de su aprovechamiento sostenible. En ese sentido la ETE (1999) resalta la fuerte amenaza de la actividad turística sobre el patrimonio por su valor económico, pues, aparte de ser de interés turístico, es aún más atractivo para las inversiones ligadas a esa actividad, las cuales podrían generar una serie de tendencias negativas. Menciona que los principales enclaves paisajísticos culturales de Europa están continuamente amenazados por la degradación: Barcelona o las islas Baleares son un claro ejemplo de los excesos de la actividad turística, como la especulación inmobiliaria, el encarecimiento de los servicios comerciales, la alteración del orden público y la vida comunitaria, la pérdida 
de identidad barrial, el cambio precipitado y polarizado de grupos socioeconómicos, entre otras consecuencias de impacto social, urbano y ambiental.

En el Perú, como en toda la región latinoamericana, se reconoce la excepcional calidad del paisaje cultural que conforma un patrimonio milenario, el cual debiera ser considerado como una sólida base para el ordenamiento y la gestión territorial, pero que en ciertos casos entra en conflicto o no compatibiliza con el interés predominante del modelo de desarrollo actual. Alguna vez existió un entendimiento entre los intereses productivos y el paisaje, la cual se quebró, quizá más intensamente con el inicio de la industrialización y el fordismo. En nombre de la "modernidad", nuevas formas de producción rompieron la relación producción-paisaje-cultura, la cual no se ha intentado recuperar o adaptar. Claro ejemplo de este equilibrio entre la adaptación y el aprovechamiento del territorio por parte de las sociedades sudamericanas prehispánicas son los milenarios sistemas de andenerías utilizadas hasta la actualidad, las cuales desde el año 1500 a. C., en conjunto con otros sistemas de infraestructura agrícola,

fueron técnicas que permitieron incrementar la productividad de los cultivos y mitigar los riesgos ambientales a fin de disminuir las variaciones climáticas anuales y así acrecentar la seguridad alimentaria. Dichos sistemas fueron producto de la estrategia tecnológica desarrollada a lo largo de tres milenios en la sierra y altiplano de Perú y Bolivia. (Kendall \& Rodríguez, 2009, p. 51)

Los objetivos del artículo corresponden a dos ámbitos: el primero abarca temas teóricos e interrelaciona secuencialmente los conceptos territorio, paisaje, cultura y patrimonio, vinculándolos con su regulación internacional y modelos integrales de gestión; y el segundo corresponde a temas de carácter aplicativo, para lo que se da referencias genéricas, y de casos prácticos sobre la valoración y gestión del patrimonio paisajístico en el Perú; y se referencia modelos de gestión del patrimonio que hayan incluido integralmente los componentes territoriales, paisajísticos y culturales.

Así, en el presente texto se indaga metodológicamente sobre referentes conceptuales y pragmáticos que permiten visualizar alcances propositivos en cuanto a la gestión integral del patrimonio paisajístico, susceptibles de ser contextualizados y aplicados en contexto del Perú y Latinoamérica.

\section{La correspondencia entre los conceptos de territorio, paisaje cultural y patrimonio}

En este capítulo se inicia la exploración de vínculos conceptuales entre territorio y paisaje cultural, para intentar fortalecer la correspondencia entre ambos, y su conjunción final en el concepto de patrimonio.

El significado de la palabra territorio, para la Real Academia de la Lengua Española (2014), tiene una connotación de pertenencia jurídica, política y administrativa, ya sea individual o colectiva, acepción con la cual la gran mayoría de hablantes identifica la palabra. Sin embargo, resulta muy limitada una definición del territorio solo en términos de injerencia legal, frecuente y craso error en la interpretación del manejo del territorio. Entonces ¿qué es el territorio? Ramón Folch brinda un alcance sofisticado: "el territorio es la matriz biofísica, es decir, aquella materia prima sobre la cual se construye la matriz ambiental o espacio territorial". Complementa dicha noción afirmando que "el territorio debe ser entendido como una malla de fenómenos, como una matriz de puntos y contrapuntos interconectados entre sí" (2011, p. 214). Eso quiere decir que el factor holístico es inherente al entendimiento del territorio. Para Folch (2011), la visión sistémica del territorio implica poder proyectarlo desde la perspectiva de las dinámicas de flujos, centros, relaciones, interfaces y superposiciones, y no una mera yuxtaposición de capas. Dichas dinámicas transforman la matriz biofísica (paisaje preantrópico), y constituyen la matriz ambiental o espacio territorial (paisaje antropizado). Por ello, "cualquier 
fragmento de territorio, natural o intervenido por el la sociedad humana, configura un paisaje, es decir, un conjunto de referentes físicos y funcionales" (p. 213).

Entonces, cualquier fragmento de territorio (intervenido o no) configura un paisaje. ¿Qué es el paisaje? En su definición, el factor de observación e interacción es esencial, pues surge de la relación y percepción sensorial por parte de la humanidad: "el paisaje es el aspecto del territorio" (Folch, 2011, p. 213), "con toda la complejidad psicológica y social que implica la percepción" (Mata, 2007, p. 157). Para la CEP (2000), paisaje es "cualquier parte del territorio tal como la percibe la población, cuyo carácter sea el resultado de la acción y la interacción de factores naturales y/o humanos" (p. 2). Entonces, la configuración formal y perceptual del paisaje es la huella, marca o señal de la sociedad humana sobre la matriz biofísica y ambiental, la cual "imprime carácter al territorio, de esta manera se produce el primer entendimiento del paisaje como patrimonio" (Mata, 2007, p. 1003).

Si cualquier fragmento de territorio configura un paisaje y refleja un carácter a partir de variadas interacciones humanas en el tiempo, entonces "aquí reside una parte muy importante de la impronta cultural sobre el paisaje" (Mata, 2006, p. 7), que en resumen se manifiesta tanto en la matriz biofísica alterada por la acción humana como en el imaginario y memoria social. Eso es lo que Sauer definió ya en 1925 como noción de paisaje cultural: "el resultado de la acción de un grupo social sobre un paisaje natural. La cultura es el agente, la naturaleza el medio y el paisaje cultural el resultado" (p. 22).

Hasta este punto se ha hilado secuencialmente los conceptos de territorio y paisaje cultural, según la bibliografía considerada, y corresponde ahora indagar sobre las regulaciones mundiales de la concepción de paisaje cultural. En primer lugar, está la Convención de la Organización de las Naciones Unidas para la Educación, la Ciencia y la Cultura (UNESCO, 2008), que en su definición de patrimonio cultural menciona que, además de los monumentos y los conjuntos de construcciones, se incluye a los lugares y zonas, planteados estos como intervenciones conjuntas entre la humanidad y la naturaleza que, así como los sitios arqueológicos, reflejan claramente "un valor universal excepcional desde el punto de vista histórico, estético, etnológico o antropológico" $(1972$, p. 15). Para la UNESCO, los "paisajes culturales ilustran la evolución de la sociedad humana y sus asentamientos a lo largo del tiempo, condicionados por las limitaciones $\mathrm{y} / \mathrm{o}$ oportunidades físicas que presenta su entorno natural y por las sucesivas fuerzas sociales, económicas y culturales, tanto externas como internas" (1972, p. 16).

Por otro lado, en las Operational Guidelines for the Implementation of the World Heritage Convention (UNESCO, 2016) se recalca que el concepto de paisaje cultural comprende una gran variedad de manifestaciones de la interacción entre la humanidad y su entorno natural, que refleja a menudo técnicas particulares de la utilización del territorio, y cuenta con una arraigada relación espiritual con la naturaleza. Asimismo, el documento menciona que la protección del paisaje contribuye a una gestión territorial adecuada, que genere la sostenibilidad de la matriz biofísica y ambiental. Las directrices mencionadas dividen a los paisajes culturales en tres categorías:

- Paisajes claramente definidos, generados intencionalmente

- Paisajes que han evolucionado orgánicamente, como resultado de condicionantes sociales, económicas, administrativas y/o religiosas

- Un paisaje fósil, en el cual el proceso evolutivo que se ha detenido

- Un paisaje continuo en el tiempo, con un rol social activo y contemporáneo

- Paisajes culturales asociativos de fuerte evocación de las asociaciones religiosas, artísticas o culturales del elemento natural ${ }^{1}$

1. Traducción libre del autor del texto original. 
Para el Instituto del Patrimonio Cultural de España (IPCE), el “Paisaje Cultural es el resultado de la interacción en el tiempo de las personas y el medio natural, cuya expresión es un territorio percibido y valorado por sus cualidades culturales, producto de un proceso y soporte de la identidad de una comunidad" (2018, párr. 1); menciona también que el futuro del paisaje depende de la actuación que se lleven a cabo en el presente, y que para asegurar su sostenibilidad depende de identificar elemento integrantes del todo paisajístico y explorar en su proceso histórico de transformación que han incidido en su configuración (IPCE, 2018, párr. 3).

Hasta aquí el artículo ha formulado un marco teórico, donde se demuestra la correspondencia supuesta entre territorio, paisaje cultural y patrimonio. Ello se complementa con los acuerdos de regulación desde organismos e iniciativas internacionales, lo cual decanta en poder saber bajo qué modelos pueden aplicarse estas teorías y normas ya en la praxis. De esta indagación surge un modelo interesante de gestión del paisaje patrimonial, los llamados parques patrimoniales, gestionados bajo una modalidad proyectual de intervención territorial

que privilegia la construcción de una imagen que otorga identidad al territorio, donde el patrimonio y otros recursos culturales y naturales se combinan, exponen, aumentan y promueven intencionadamente para formar un paisaje acordado, convenido que cuenta la historia de dicho territorio y sus residentes. (Pérez \& Parra, 2004, p. 10)

O, como lo sintetiza Pablo Alonso (2014), "instrumentos de ordenación y gestión de la renta territorial que una determinada área ostenta y produce" (p. 221).

Dicha metodología de gestión está muy difundida en la UE y en los EE. UU., donde se emplea para plantear proyectos a escala regional, los cuales son gestionados por diversos actores a distintos niveles, con el objetivo de alcanzar el desarrollo económico a partir de la puesta en valor de elementos patrimoniales gestando una "marca" orientada a ser un producto turístico, todo ello sin controlar los usos del suelo o su propiedad (Alonso, 2014). Sabaté (2009) concibe la idea de los parque patrimoniales como una herramienta de proyección y gestión, "que implica garantizar en un determinado paisaje cultural la preservación de sus recursos patrimoniales" (p. 8) mediante su puesta en valor, para que actúe como un dinamizador productivo y económico local. A nivel legislativo se puede citar lo planteado por la Ley de Parques Culturales de Aragón que en su artículo I (1997), conceptualiza un parque patrimonial como "un territorio que contiene elementos relevantes del patrimonio cultural, integrados en un marco físico de valor paisajístico y/o ecológico singular, que gozara de promoción y protección global en su conjunto, con especiales medidas de protección para dichos elementos relevantes" (p. 3).

Finalmente, a manera de síntesis de esta primera parte, es posible sostener que se entiende como territorio a la materia primigenia biofísica y ambiental (Folch, 2011), la cual se reconoce mediante la observación e interacción espacial, concibiendo la percepción del paisaje con toda la complejidad psicológica y social que implica aquella apreciación (Mata, 2007). Por ende, el paisaje posee y trasmite un carácter en permanente construcción, que define un paisaje cultural particular e identitario, el cual a su vez refleja un determinado espacio y tiempo social (UNESCO, 1972). El paisaje cultural es aquel binomio donde el paisaje (matriz biofísica-ambiental) y la cultura (testimonio social) se constituyen como la base de un nuevo orden en el territorio, conformando un concepto único: el patrimonio (Sabaté, 2005), donde la figura de parque patrimonial cobra mayor relevancia a nivel mundial para la gestión activa de las áreas patrimoniales (Bray, 1994).

\section{La situación genérica de la valoración y gestión del paisaje patrimonial en relación a su aprovechamiento productivo en el Perú}

Los procesos urbanos y territoriales son de gran interés para analizar el desenvolvimiento de los modelos de desarrollo aplicados, ya que esa dinámica depende de una 
serie de intereses de uso demandados por diferentes grupos sociales en torno a diversos tipos de productividad, los cuales alteran y/o impactan en mayor o menor grado la matriz biofísica donde se desarrollan. La planificación urbana y la ordenación territorial son, en teoría, instrumentos de gestión pública que se emplean para proyectar y regular las diversas funciones productivas, de servicios, infraestructura y habitabilidad que se producen sobre un determinado espacio en el tiempo. Desde la perspectiva de Folch (2011), consiste "en determinar qué va dónde y para qué, siempre que este 'dónde' lo consienta, este 'para qué' responda a una intención civil de interés general y este 'qué' tenga calidad y sentido. El urbanismo planifica y proyecta el territorio, construyendo la matriz ambiental" (p. 216)

En el Perú el Acondicionamiento Territorial y Desarrollo Urbano (nombre con el cual está definido en el Decreto Supremo 004-2011-MVCS²) es una normativa instrumental (está incluido su vínculo con la Zonificación Ecológica y Económica³) que aún no ha tenido real relevancia aplicativa en el modelo político de desarrollo del país, por lo que son muy escasas las consideraciones ambientales y paisajísticas. Por ello, podría decirse que las actividades primarias y terciarias sin gestión aplicada dentro de un marco de planificación urbana y territorial han determinado casi por completo la conformación del paisaje cultural de los territorios y ciudades del Perú: resulta de ese escenario una dialéctica muchas veces conflictiva y discordante. Sobre esta situación, Alex Tarroja (2006) sostiene lo siguiente:

El resultado de las transformaciones urbanas y rurales a escala regional y falta de cultura de gestión de los espacios abiertos ha originado una creciente degradación de los paisajes. Pero el hecho más preocupante es que esta degradación no se limita tan sólo a una pérdida de calidad ecológica y estética del paisaje, sino que afecta, y quizá aún en mayor medida los valores sociales y culturales del paisaje. (p. 2)

Al respecto se puede mencionar varios ejemplos de elevado impacto ambiental, social, económico y mediático en el Perú, los cuales demuestran la disonancia de compatibilidad entre las aptitudes y valoraciones del paisaje cultural, y las transformaciones y demarcación del territorio con fines productivos-extractivos a gran escala. Tales transformaciones están principalmente relacionadas con la actividad minera y energética, tanto en entornos rurales como urbanos, como por ejemplo Bagua (región Amazonas, por la afectación sobre territorios de comunidades indígenas de la Amazonía), Islay (región Arequipa, por el proyecto minero Tía María), Conga (Región Cajamarca, por la actividad de la minera Yanacocha), Cotabambas (Región Apurímac), o Cerro de Pasco, donde la actividad minera construye y destruye ciudad cotidianamente desde hace casi 400 años. En el caso de la región Lima, están los distritos de Pachacamac y Villa María del Triunfo (por la presencia de Cementos Lima), Lurín (por la presencia de explosivos EXSA), entre otros. Al respecto, Alonso (2014) plantea que el complejo entendimiento entre la intensa productividad económica y el patrimonio sea el resultado de una intrínseca correspondencia entre las ciencias sociales y la ordenación territorial, donde la concordancia lleve a considerar temas antropológicos/etnográficos, económicos, ambientales, urbanos, turísticos, mediáticos, entre otros componentes específicos. Por ello, afirma que "resulta difícil disgregar aspectos técnicos de proyección y gestión de la dimensión sociocultural" (p. 22).

\footnotetext{
2. Reglamento de acondicionamiento territorial y desarrollo urbano. Ministerio de Vivienda, Construcción y Saneamiento. Decreto Supremo 004-2011. Dirección Nacional de Urbanismo - Dirección de Ordenamiento Territorial.

3. Considerada en el artículo 11 de la Ley № 26821 Ley Orgánica para el Aprovechamiento Sostenible de los Recursos Naturales, 1997. Dicho artículo plantea la Zonificación Ecológica y Económica como "apoyo al Ordenamiento Territorial, a fin de evitar conflictos por superposición de títulos y usos inapropiados, y demás fines. La Zonificación se realiza en base a áreas prioritarias conciliando los intereses nacionales de la conservación del patrimonio natural con el aprovechamiento sostenible de los recursos naturales".
} 
Dichas divergencias entre la valoración del paisaje cultural y la productividad económica han generado cambios en sus relaciones de gestión. Por parte del Servicio Nacional de Áreas Naturales Protegidas por el Estado peruano (SERNANP4), se ha propiciado la regulación y conservación del paisaje cultural patrimonial en asociación con las actividades productivas locales y regionales, y emprendimientos turísticos, como se plantea más adelante. Las iniciativas de gestión del paisaje cultural patrimonial relacionadas con la actividad turística en tanto generadora de desarrollo económico local $\left.\right|^{5}$ se han aplicado mediante nociones de turismo rural comunitario ${ }^{6}$ orientadas a propiciar la participación activa de las comunidades locales considerando las actividades económicas tradicionales, como la agricultura, ganadería, pesca, artesanía y vivencia propia como parte del producto turístico. Este tipo de iniciativas se han gestionado desde el Estado (central, regional y local), organizaciones no gubernamentales y empresas privadas, aunque con cierto enfoque sesgado, que no implica la compresión total de las dimensiones integrales y multidimensionales del producto turístico patrimonial que pretenden promover. Para Tarroja (2006), gestionar el paisaje cultural patrimonial implica el diálogo y creatividad entre múltiples disciplinas relativas a las formas del territorio, así como a su percepción y valoración social, lo cual le otorga al paisaje la capacidad para establecer una aproximación global, integrada, que articule las interrelaciones entre elementos y procesos de naturaleza ecológica, económica, social, cultural, urbanística, estética, etc.

Al respecto cabe citar la Carta Internacional del Turismo Cultural, texto que reúne directrices sobre la gestión del turismo en lugares de importancia patrimonial (ICOMOS, 1999), la cual resalta que es crucial (a) hacer a las comunidades locales partícipes de la ordenación del patrimonio, facilitando su emprendimiento y la promoción turística del recurso patrimonial en cuestión; (b) facilitar y fomentar un diálogo entre los intereses de la conservación y la industria turística (aunque bien podría referirse la industria en general ${ }^{7}$ ) sobre la importancia y fragilidad de los paisajes culturales patrimoniales; y (c) generar planes y políticas de gestión consecuentes con la puesta en valor del patrimonio (término al que podría añadirse el territorio ${ }^{8}$ ).

El interés por el aprovechamiento del paisaje cultural patrimonial va mucho más allá de fines turísticos: el factor turístico es únicamente una motivación más para valorar la integralidad de la matriz biofísica y ambiental, destacando sus "aspectos relativos a la calidad de vida de los ciudadanos, la memoria colectiva, la identidad local y el valor del patrimonio como activo o capital territorial para el desarrollo regional" (Tarroja, 2006, p. 44).

\section{Buenas prácticas de la valoración y gestión del paisaje patrimonial en re- lación a su aprovechamiento productivo en el Perú}

A continuación se resaltan tres casos prácticos de iniciativas sobre valoración y gestión del paisaje cultural patrimonial, desde escalas territoriales diferenciadas, dentro del marco de los conceptos previamente planteados en la primera sección.

\footnotetext{
4. El SERNANP pertenece al Sistema Nacional de Área Naturales Protegidas, parte del Ministerio del Ambiente. Las áreas naturales protegidas ocupan más del $17 \%$ del territorio del Perú, y desde 2011 han recibido más de un millón de visitantes.

5. Para conocer sobre estos emprendimientos promovidos desde el estado y su enfoque visitar: http:// www.turismoruralcomunitario.com.pe/y http://www.sernanp.gob.pe/turismo-en-anp

6. Es toda actividad turística que se desarrolla en el medio rural, de manera planificada y sostenible, basada en la participación de las poblaciones locales organizadas para beneficio de la comunidad, siendo la cultura rural un componente clave del producto. Programa Nacional de Turismo Rural Comunitario, Ministerio de Comercio Exterior y Turismo Perú.

7. Comentario del autor.

8. Comentario del autor.
} 


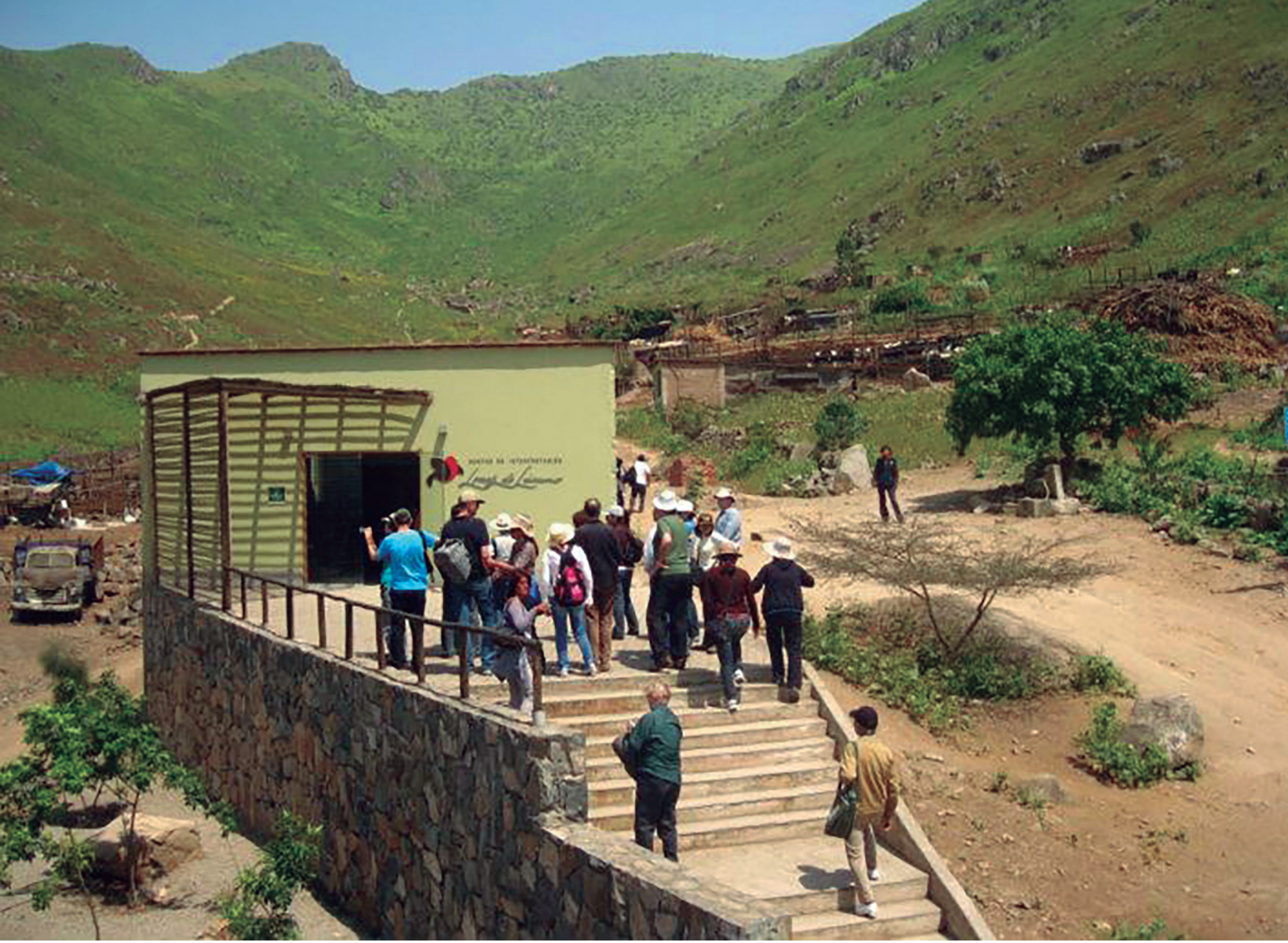

El primer caso es el del Circuito Ecoturístico de las Lomas de Lúcumo, en el distrito de Pachacamac (valle del río Lurín, Lima), donde la comunidad del Centro Poblado Rural Quebrada Verde, dedicada principalmente a la ganadería y agricultura, desde principios de la década de 1990 percibe, reconoce y valora un patrimonio de lomas estacionales, las cuales decidieron conservar y poner en valor con fines turísticos, para su aprovechamiento sostenible, como una alternativas de beneficio económico local (se han rescatado alrededor de $150 \mathrm{Ha}$.).

El segundo caso corresponde a la Reserva Paisajística Nor Yauyos - Cochas (RPNYC), ubicada entre la región Lima y Junín, un amplio territorio altoandino (más de 200,000 Ha.) declarado Zona de Reserva Turística Nacional en 1996 gracias a la iniciativa y los esfuerzos locales provenientes de la Sociedad Agrícola de Interés Social Túpac Amaru. En este proceso la formación de la Corporación de Desarrollo del Nor Yauyos en 1997 fue determinante para que dos años después se promulgue como Zona Reservada Alto Cañete y Cochas - Pachacayo, y posteriormente como Reserva Paisajística Nor Yauyos - Cochas (2001) por parte de SERNANP. Dicha promulgación tiene como objetivo proteger ecosistemas inmersos en un conjunto paisajístico de gran belleza y singularidad, que coexisten en armoniosa relación con las actividades ancestrales de las comu-
Figura 1. El ecosistema de Lomas de Lúcumo y sus equipamientos turísticos, 2010. Archivo fotográfico del proyecto Vive Pachacámac, Lima, Perú.

9. Las SAIS fueron figuras asociativas creadas en la década de los 70 como parte de la aplicación de la Reforma Agraria en el Perú. Esta figura promovía la creación de empresas asociativas bajo un régimen de propiedad colectiva. 


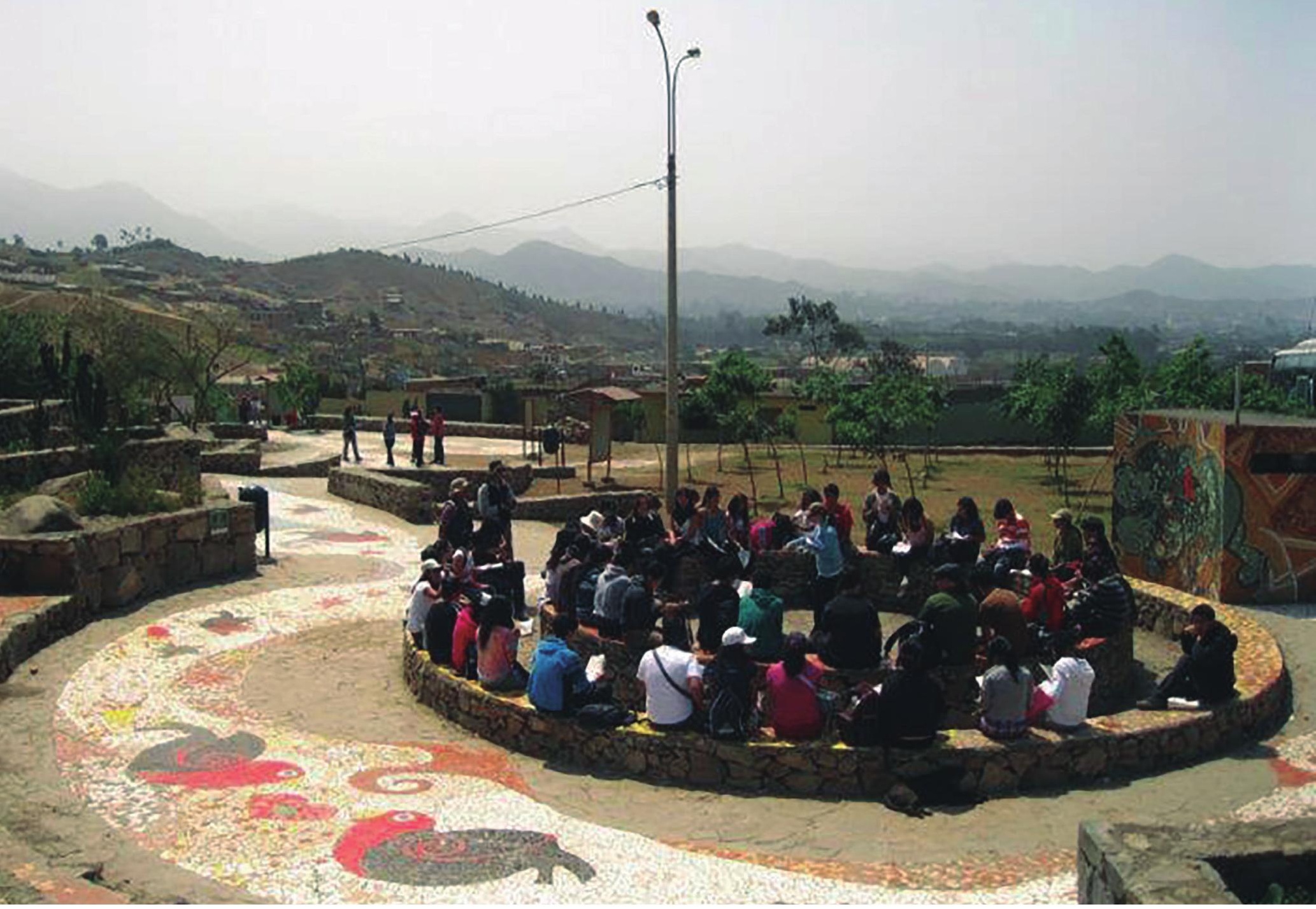

Figura 2. Talleres en temas de valoración ambiental en el Centro Poblado Rural Quebrada Verde, 2010. Archivo fotográfico del proyecto Vive Pachacámac, Lima, Perú. nidades campesinas, las cuales han desarrollado formas de organización social para la producción y el uso eficiente de sus recursos patrimoniales.

El tercer caso es el Valle del Colca, y su ancestral relación territorial y cultural con la Reserva Natural Salinas y Aguada Blanca, y el Valle de los Volcanes en Andagua (región Arequipa). Se trata de un caso similar al de la RPNYC, aunque cuenta con un territorio más vasto en relación a la cuenca del Colca-Majes-Camaná. En estos territorios puede observarse el impacto de la presencia de las culturas Wari y Tiwanaku (De La Vera Cruz, 2010), cuya ocupación se remonta a aproximadamente 10,000 años a. C. Debido a estas cualidades, la Autoridad Autónoma del Colca y Anexos promueve desde 2015 un proyecto para que UNESCO declare el Valle de los Volcanes y del Colca como un geoparque mundial $^{10}$, etiqueta que brinda el reconocimiento gubernamental de la importancia de la gestión holística de los sitios geológicos y paisajes destacados. En las siguientes secciones se amplía la información sobre cada uno de los casos mencionados.
10. Los geoparques mundiales de la UNESCO cuentan la historia de 4.600 millones de años del planeta Tierra y de los acontecimientos geológicos que le dieron forma, así como la evolución de la humanidad misma. No solo muestran evidencia de los cambios climáticos en el pasado, sino que también informan a las comunidades locales de los desafíos actuales, y las ayudan a prepararse para sucesos como terremotos, tsunamis y erupciones volcánicas. 


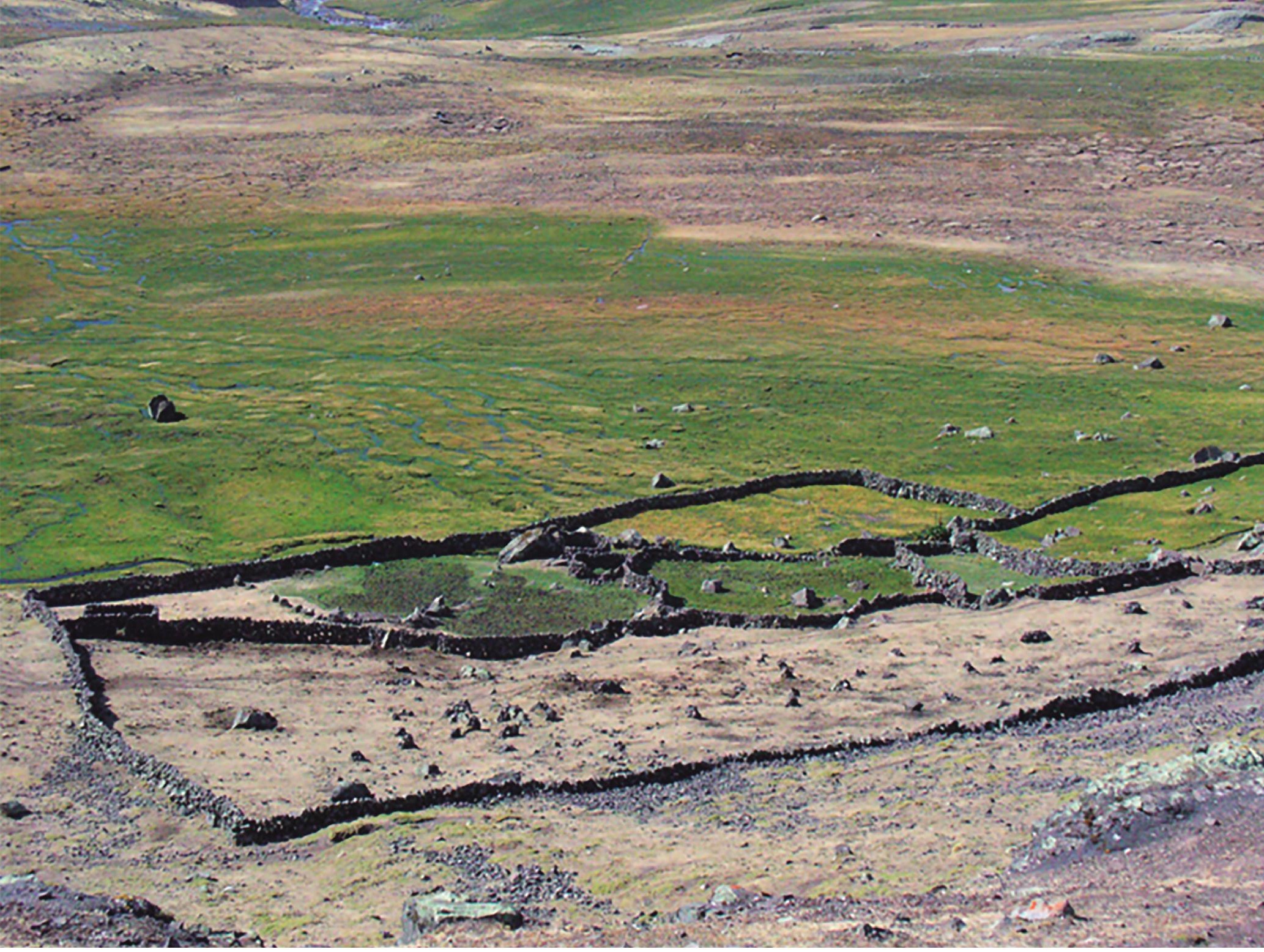

\section{El circuito ecoturístico Lomas de Lúcumo, Centro Poblado Rural Quebrada Verde ${ }^{11}$}

Las Lomas de Lúcumo forman parte de toda una cadena de ecosistemas de lomas que en un momento bordearon las áridas franjas costeras de Lima. Este fue producido por un fenómeno climático de neblinas que sirve de sustento para diversas funciones ambientales, pero poco a poco fue depredado y urbanizado, hasta llegar casi a su desaparición. Hace 25 años, dicho patrimonio paisajístico fue valorado por la comunidad de Quebrada Verde, con la intención de rescatar lo que subsistía de dicho ecosistema. Se inició entonces un proceso de largo aliento para poner en valor ese legado patrimonial: se creó el Comité de Turismo de Quebrada Verde (1996), que en conjunto con la comunidad y diversas organizaciones trabajó por reconocer la trascendencia ambiental, paisajística y cultural de este hábitat para el distrito de Pachacamac, y la ciudad de Lima (Figura 1).

Actualmente la gestión del circuito Lomas de Lúcumo ha iniciado una etapa pos proceso de puesta en valor (adecuación de caminos para los visitantes, construcción del centro de interpretación y espacio público de recepción al circuito, capacitación de guías locales, promoción como producto turístico, etc.), ya que el circuito ha alcanzado un cierto posicionamiento en la conciencia de la población limeña y las autoridades; forma parte del Programa Lomas de Lima' ${ }^{12}$, de la Municipalidad Metropolitana, orientado a la recu-
Figura 3. Estancias de pastores como unidad territorial básica de uso y manejo del espacio a nivel de usufructo ganadero, mediante una ocupación estanciera semipermanente, lo cual permite mayor accesibilidad a los pastos durante todo el año. En Apu Pariacaca y el Alto Cañete, Estudio de Paisaje Cultural (p. 190), por C. Abad, J. González \& A. Chamorro, 2012, Lima, Perú: Instituto Nacional de Cultura. 


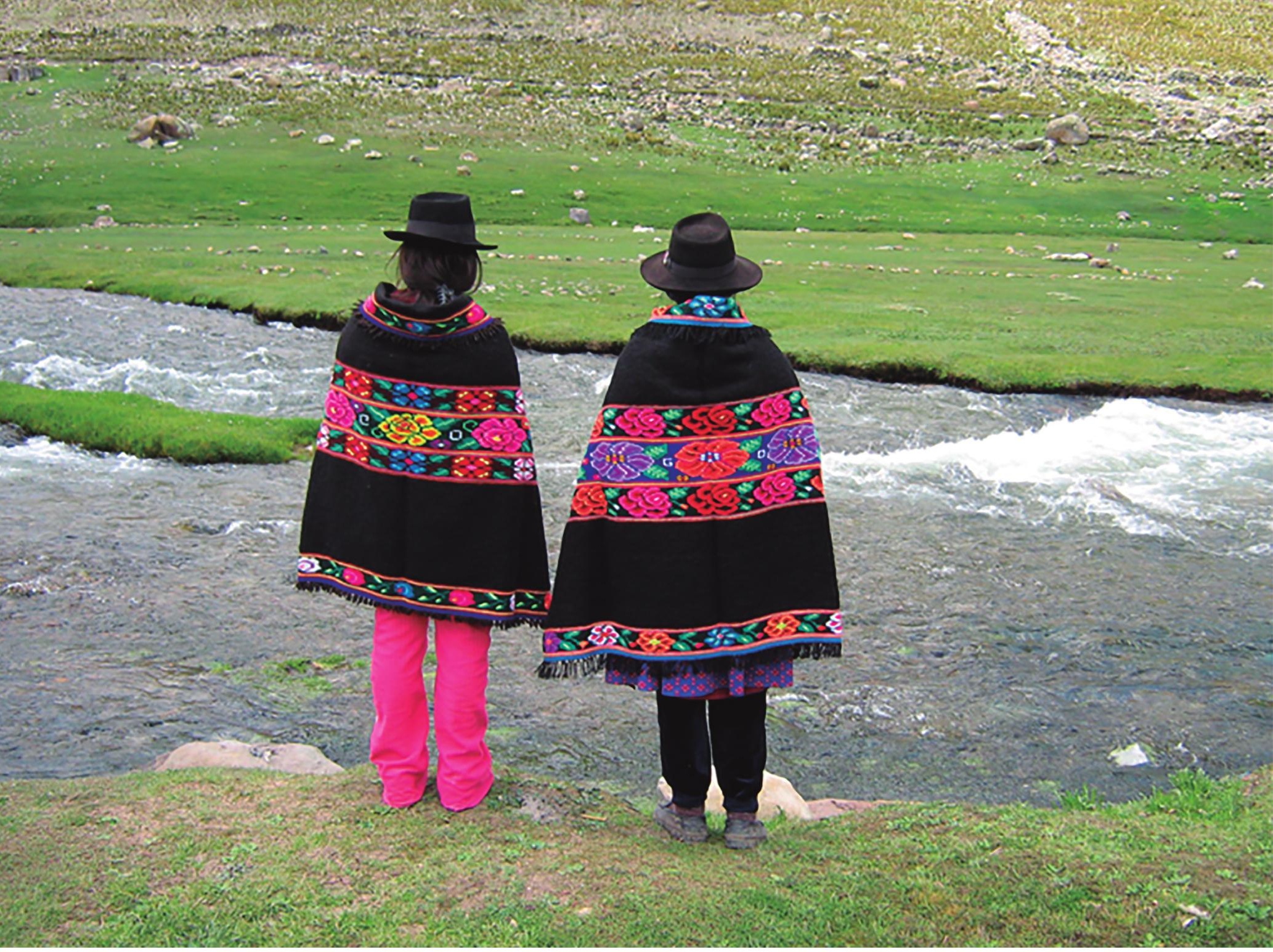

Figura 4. Niñas con mantas labradas en las zonas altoandinas de la Reserva Paisajística Nor Yauyos - Cochas. En Apu Pariacaca y el Alto Cañete, Estudio de Paisaje Cultural (p. 260), por C. Abad, J. González \& A. Chamorro, 2012, Lima, Perú: Instituto Nacional de Cultura. peración dichos ecosistemas; ha sido reconocido como ecosistema frágil el Ministerio de Agricultura $^{13}$, y recibe el apoyo del Ministerio de Comercio Exterior y Turismo (Figura 2).

El circuito ecoturístico de la Lomas de Lúcumo es un ejemplo de cómo la iniciativa autogestionaria comunitaria, desarrollando alianzas públicas y privadas estratégicas, puede lograr resultados tangibles y exitosos de gestión del paisaje patrimonial. Lo más importante y trascendente para asegurar dicha sostenibilidad es que se ha sabido consolidar en el entendimiento de la comunidad, la pertenencia y la valoración del recurso patrimonial14.

\section{La Reserva Paisajística Nor Yauyos - Cochas ${ }^{15}$}

Las reservas paisajísticas son áreas destinadas a la protección de ambientes cuya integridad geográfica muestra una armoniosa relación entre la acción humana y la naturaleza, y que albergan importantes valores estéticos naturales y culturales (SERNANP,

13. Según Resolución ministerial Nº274-2013-MINAGRI

14. En los indicadores para la formulación del proyecto Vive Pachacámac, Formación de capacidades y puesta en valor de recursos comunitarios para el fomento del turismo rural en el distrito de Pachacámac (2008, ONG Grupo GEA), se señala que en el CPR de Quebrada Verde se contaba con un plan de desarrollo turístico vigente, y que buen porcentaje de su población había recibido y logrado asimilar las enseñanzas vertidas en capacitaciones relacionadas al emprendimiento turístico y de microempresa.

15. La reserva cuenta con un blog: http://rpnycperu.blogspot.com.es/. 


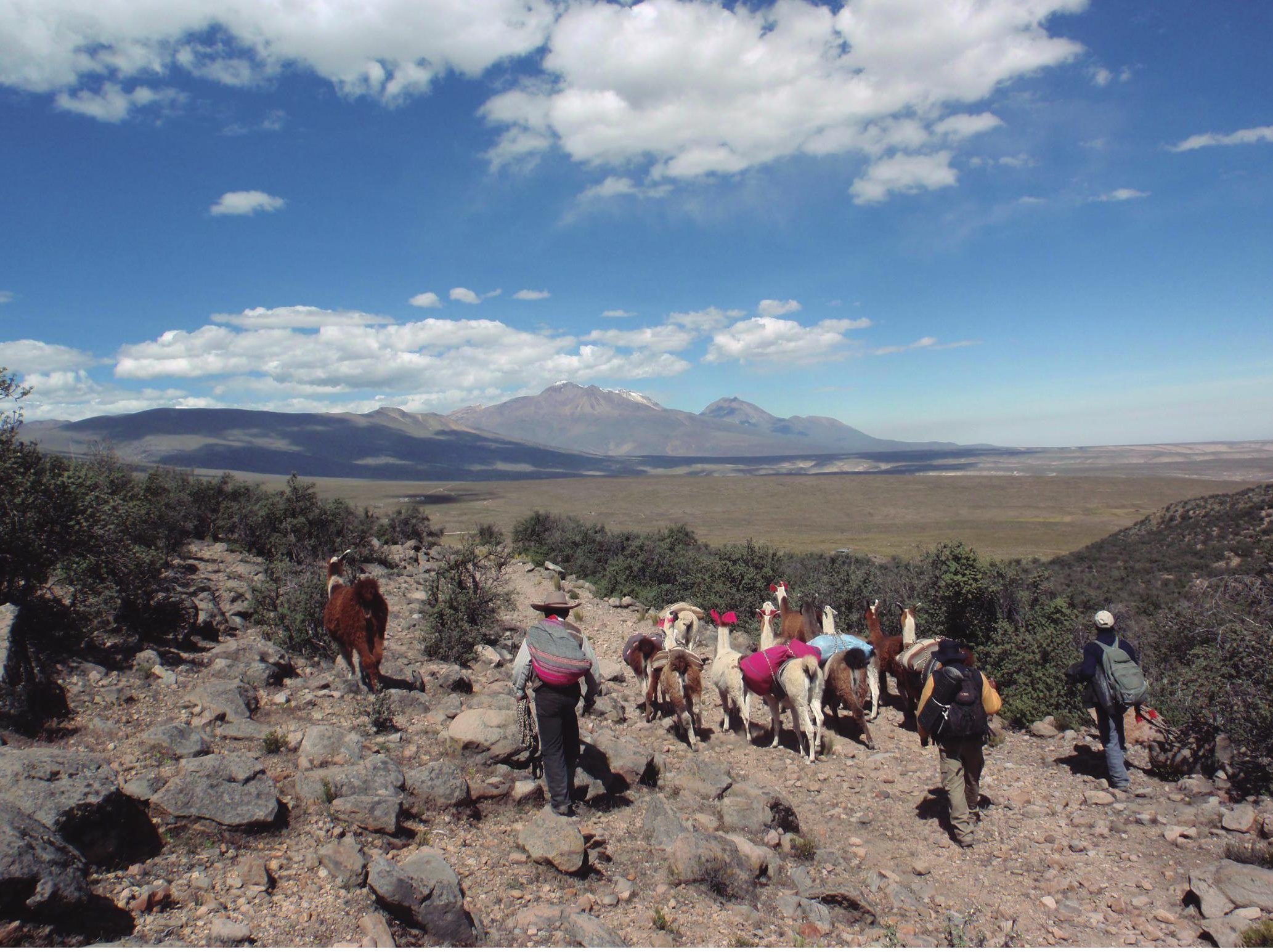

$2005)^{16}$. La RPNYC está categorizada como área natural protegida (ANP), lo que implica la consideración de un área con uso directo, es decir, un aprovechamiento productivo por parte de los grupos humanos que la habitan. Según la zonificación del Plan Maestro de la RPNYC 2006-201117, coordinado por el SERNANP (2006), la reserva se ciñe a la definición de paisaje de la CEP (2000). Por lo tanto, a diferencia de otras ANP en las cuales los atributos de conservación son una especie endémica de flora o fauna, con muy poca intervención de actividades humanas, en las reservas paisajísticas las prioridades están vinculadas al mantenimiento del paisaje (relación persona-naturaleza). Así mismo, la CEP menciona que el paisaje "es un elemento importante de la calidad de vida de las poblaciones", y "constituye un elemento esencial del bienestar individual y social" (2002, p. 1). De esta manera, en el Plan Maestro de la RPNYC 2006-2011 se reconoce que las actividades antrópicas que se llevan a cabo en la reserva modelan el paisaje; por lo tanto, si estas se dan de forma desorganizada y desmedida, se corre el riesgo de que ocasionen impactos importantes no solo en el entorno paisajístico sino también en la calidad de vida de las poblaciones circundantes (Figura 3).
16. Actualmente solo existen en el Perú dos reservas con estas cualidades: la de Nor Yauyos - Cocha y la Subcuenca del Cotahuasi, en la región Arequipa.

17. Existe una nueva actualización aprobada del plan maestro con horizonte 2016-2020, mediante Resolución Presidencial N²07-2016-SERNANP.
Figura 5. Arrieros con llamas entre un bosque de queñuales, 2011. Archivo fotográfico del proyecto Santuario Alto Andino de las Aves. Arequipa, Perú. 


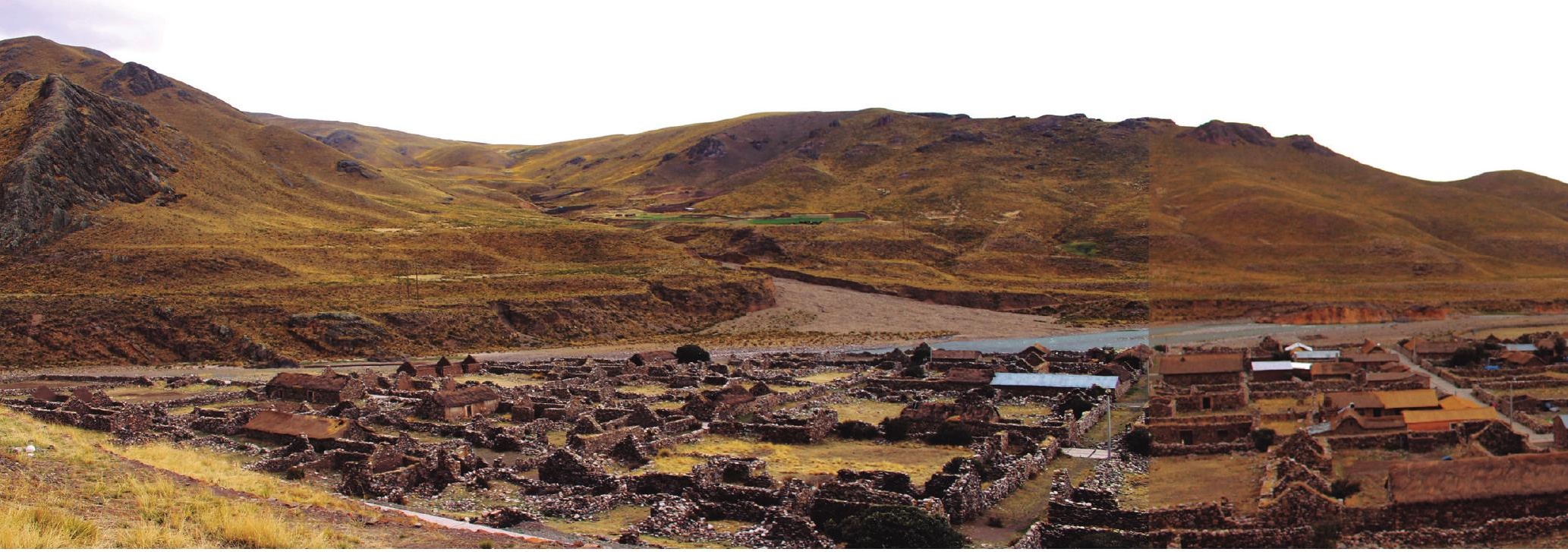

Figura 6. Sibayo Rumillacta (en español, "pueblo de piedra"), pueblo de la cuenca alta del Valle del Colca. Fotografía por I. Ramírez, 2012.
Unos de los atractivos emblemáticos de la RPNYC es el Camino Inca o Qhapaq Ñan, en conjunto con el nevado apu Pariacaca. Al respecto, en el ex Instituto Nacional de Cultura (actualmente Ministerio de Cultura), desde la Unidad de Estudios Geográficos, se elaboró en 2009 el estudio titulado Apu Pariacaca y el Alto Cañete. Estudio de Paisaje Cultural. Tal investigación explica la trascendencia de estos territorios: el apu Pariacaca (5,860 metros de altitud) es el punto más relevante del Camino Inca en el Chinchaysuyu, extensión del camino que comunicaba de manera transversal el centro administrativo-religioso Pachacámac (Lima), en la costa peruana, con el centro administrativo en la sierra central, Xauxatambo (Junín). Ambos santuarios, Pariacaca y Pachacámac, unidos por el Qhapaq Ñan, eran considerados como los más importantes de ese sector del Tawantinsuyu, y fueron escenario de grandes hazañas de dioses y de poblaciones aledañas. Su relevancia patrimonial conjuga paisaje, historia, mística, geografía, arte, etnografía, biología y arquitectura, además de otras particularidades.

El estudio de este paisaje cultural constituye el primer piloto que abarca los territorios de las comunidades campesinas de Tanta (provincia de Yauyos) y Huachipampa (provincia de Huarochirí). En él se propone principalmente emplear una metodología de valoración del paisaje que permita, según las diversas dinámicas de este, prorizar criterios arqueológicos, socioculturales y físico-geográficos, para finalmente anexar la variable patrimonial. De esta manera se posiciona al paisaje como una categoría que condiciona la gestión territorial, donde el patrimonio es el elemento transversal en los planteamientos de cualquier estrategia de desarrollo territorial. La mencionada investigación concluye en el planteamiento de posibles tendencias en la dinámica del paisaje, a manera de consideraciones sobre los retos que afrontarán estos territorios en el futuro, en relación a su fragilidad ante el cambio climático global y los fenómenos sociales como la crisis hídrica; la migración; los cambios en el manejo productivo; el aumento del turismo, la actividad urbana y la construcción de infraestructuras; la desaparición del intercambio tradicional (trueque); y la degradación de los restos arqueológicos.

Tomando en cuenta que solo existen dos reservas paisajísticas en el Perú, con la creación de la RPNYC se marca un hito, pues pone de manifiesto la voluntad del Estado de conservar estos modelos de gestión territorial milenarios, que implican la creación de sistemas territoriales de gran estética, origen de la cosmovisión y de la identidad. Son en estos paisajes donde el patrimonio cobra mayor vigencia, donde se organizan en armonía las actividades económico-productivas con las formas de organización social.

\section{La Reserva Natural Salinas y Aguada Blanca, el Valle del Colca y el Valle de los Volcanes $^{18}$}

En este caso se trata de tres territorios extensos, ligados entre sí por sus cualidades geográficas y etnográficas. En primer lugar, está la Reserva Nacional de Salinas y Aguada

18. http://www.colcaperu.gob.pe/inicio 


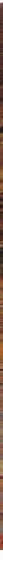

Blanca ${ }^{19}$, creada con el fin de garantizar la conservación de los recursos naturales -su particular fauna de aves y camélidos, sus bosques y pastos, lagunas y humedales ${ }^{20}$, salares y volcanes- y propiciar su utilización racional de parte de la población mediante actividades productivas tradicionales y no tradicionales, como el turismo. El área que ocupa la reserva, que se encuentra bajo la administración del SERNANP y el Ministerio de Agricultura, está extensamente poblada, por lo que se determinó que las decisiones sobre las acciones que realizar en el interior de esta deben tomarse en concordancia con los intereses de los pobladores. Actualmente la gestión de la reserva está siendo realizada bajo el recientemente aprobado Plan Maestro 2016-2020 (ver Figura 5).

En cuanto al Valle del Colca, se encuentra allí valioso testimonio de la acción prehispánica, inca y colonial. Los restos arqueológicos y templos coloniales existentes en cada uno de los pueblos de ambas márgenes del río Colca son elementos artísticos y arquitectónicos dignos del mayor aprecio y cuidado. Se trata de uno de los lugares con mayor muestra de mestizaje y sincretismo cultural: sus actuales etnias residentes son los cabanas y los collaguas, que conservan los rasgos de una cultura milenaria sostenida en la tradición campesina, ganadera y comercial (Quiroz, 2010).

El Programa Patrimonio para el Desarrollo de la Agencia Española de Cooperación Internacional elaboró en 2009 la propuesta del Plan de Acondicionamiento Territorial del Valle del Colca, el cual ordenaría los espacios distritales que conforman el valle en cuestión, en el ámbito de la subcuenca del río del mismo nombre (provincia de Caylloma), como un instrumento normativo y de manejo para el aprovechamiento sostenible de los recursos naturales, los valores culturales, la distribución equilibrada de la población, y el desarrollo de la inversión pública y privada en los ámbitos urbano y rural del territorio. Dicho plan de acondicionamiento territorial partía del principio de que "la inversión en la conservación del patrimonio valoriza la identidad cultural, consecuentemente, constituye una estrategia efectiva de desarrollo sustentable e incluyente en el territorio" (p. 3). El patrimonio del Valle del Colca ha logrado un reconocimiento nacional e internacional, constituye un "sello" del territorio: por consiguiente, a partir de un acondicionamiento territorial con medidas de protección y de renovación de su infraestructura, servicios y equipamiento, pueden generarse las condiciones para establecer y consolidar una economía cultural como fundamento de sostenibilidad y canalización de los beneficios hacia la población local, y no solo hacia unos pocos individuos o empresas, generalmente foráneos. El plan, hasta la fecha, lamentablemente es un documento sin aprobación normativa ni valor legal (ver Figura 6).

\footnotetext{
19. Establecida en 1979, en un área de más de 300,000 Ha.

20. Los cuales han sido reconocidos por la Convención RAMSAR, que vela por la conservación de humedales de importancia a nivel mundial.
} 



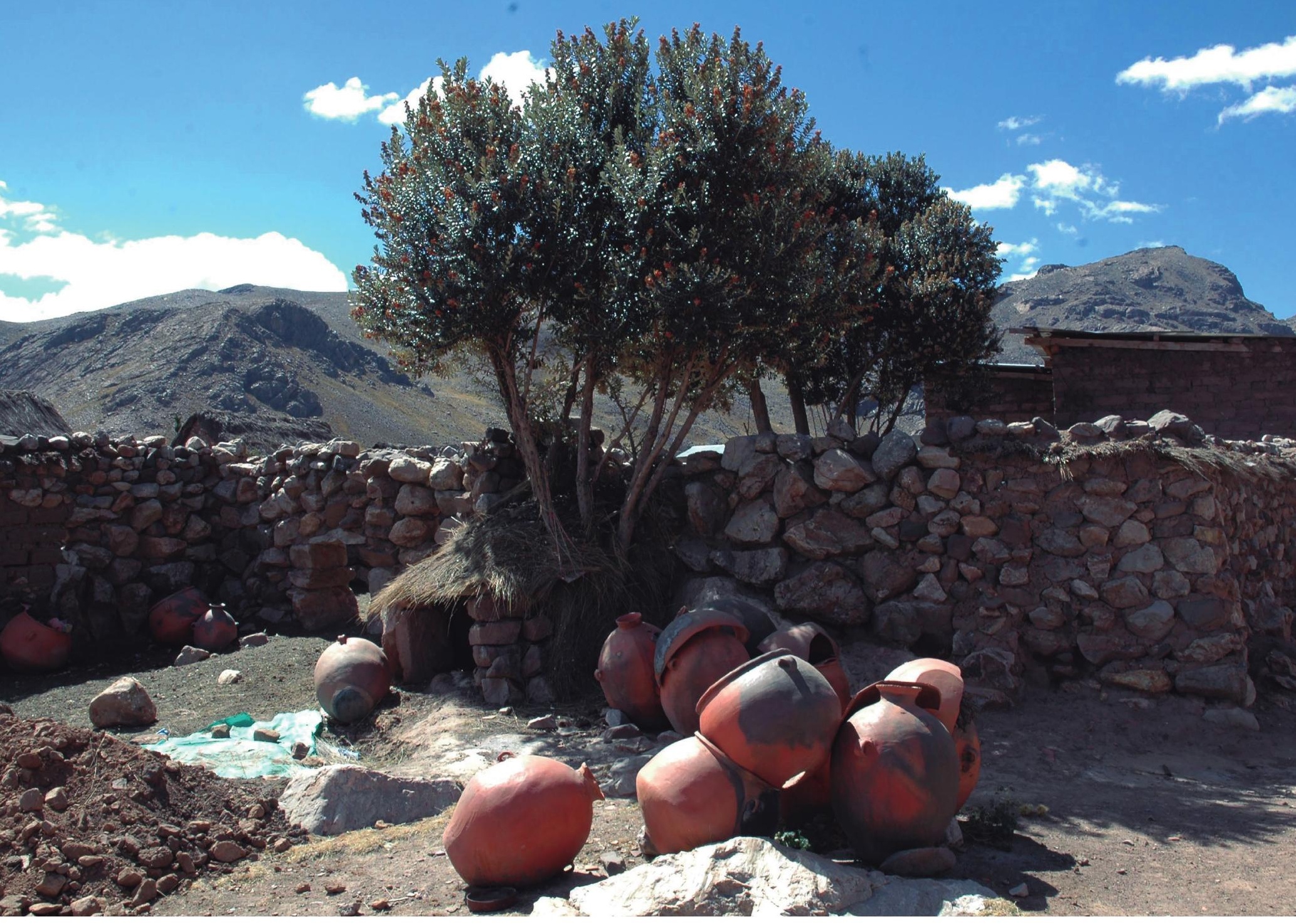

\section{Conclusiones}

Discutir sobre territorios es discutir sobre el paisaje cultural y su resultante patrimonial, entendiendo y reflexionando sobre la historia, y las implicancias del modelo de desarrollo o valoración social implantado sobre aquella matriz biofísica, que ha impactado en su configuración, transformándola, ya sea de manera sabia o negligente.

Mediante los referentes teóricos analizados y la revisión de los principales acuerdos internacionales de regulación del paisaje cultural (ETE, CEP, UNESCO, IPCE), se ha validado una relación de lógica correspondencia y secuencial entre los conceptos de territorio, paisaje, cultura y patrimonio. Con ello se puede reconocer que dicha lógica se adecúa a un modelo de gestión integral denominado parque patrimonial, con el objetivo de generar desarrollo económico local reconociendo las patologías de la valoración del paisaje cultural, para así poder definir directrices que lleven a cabo una puesta en valor responsable de los recursos patrimoniales como potenciales productos turísticos.

Los referentes teóricos y prácticos han permitido argumentar que las intervenciones antrópicas a mayor o menor escala sobre el paisaje son permanentes o, en los casos más incólumes, muy latentes. El paisaje cultural es un patrimonio constantemente en evolución (física y social), y su inevitable transformación puede ser de alguna manera controlada y orientada, de forma que se conservando conserven los "rasgos esenciales que le dan carácter y personalidad" (Nogué, 2006, p. 139). Es necesario repensar las maneras de aprovechar el patrimonio paisajístico, recuperando la concordancia entre las necesidades productivas y la intervención del territorio para estos fines. Esta es la cuestión de mayor complejidad, pues mientras el modelo de desarrollo continúe si-
Figura 8. Vivienda tradicional en el Valle de Andagua. Archivo fotográfico de la Organización de Destino de Valle de los Volcanes, recuperado de http://vallevolcanesperu.pe/es/galvolcanes/ 
Tabla 1. Cuadro básico comparativo. Coincidencias entre casos catalogados como buenas prácticas y el modelo de parque patrimonial

Circuito

Ecoturístico

de las Lomas

Lúcumo

RPNYC

RNSAB, Valle

del Colca y

Andagua
$\mathrm{X}$

$x$

Asociación de diversos gestores sociales a distinta escalas y funciones
Participación de diversas especialidades sociales y técnicas
$\mathrm{X}$

$\mathrm{X}$

Objetivo: desarrollo económico a partir de la puesta en valor de elementos patrimoniales, el reconocimiento de la identidad local y la creación de un producto turístico

Sin control estricto en la propiedad del suelo usufructo

$x$

Elaboración propia a partir de "La transición al pos-productivismo: parques patrimoniales, parques culturales y ordenación territorial", por P. Alonso (2014), EURE: Revista Latinoamericana de Estudios Urbanos Regionales, 40(119), 217-238.

guiendo algunos patrones globales radicales, como los altos niveles de extractivismo y monocultivo, los territorios más vulnerables (meteorológica y políticamente) serán los más afectados por las demandas de dicho modelo.

Justamente, en el proceso de compatibilizar la puesta en valor del paisaje patrimonial con los fines productivos, de plantear una ordenación territorial, afloran varias cuestiones. Por ejemplo, surge la siguiente pregunta: “¿Cómo traducir la identidad del paisaje a la ordenación y gestión territorial?" (Alonso, 2014, p. 219). En ese sentido, el modelo de parque patrimonial vuelve a aparecer como un producto híbrido de componentes productivos, académicos y gestión institucional, integrando las actividades económicas locales, la investigación científica, la museología en espacios cerrados o al aire libre, los ecomuseos como expresión de la cultura viva, el deporte, la oferta turísti$\mathrm{ca}$, entre otras funciones que fomenten las rentas territoriales asociadas al patrimonio (Alonso, 2014, p. 221).

Tomando como referencia los casos definidos como ejemplos de buenas prácticas, es posible afirmar que la gestión inteligente de los recursos patrimoniales es un factor clave para el desarrollo económico. La gestión patrimonial conserva la tradición local, genera actividades alternativas y puestos de trabajo, y atrae inversiones turísticas y sus derivados; además, muy fundamentalmente, refuerza la autoestima de la comunidad en una "dimensión espiritual, ideológica y simbólica" (Nogué, 2006, p. 135). 
Además, las buenas prácticas señaladas representan la acción conjunta de diversas organizaciones sociales, públicas y privadas, de forma que engloban diversas perspectivas de saberes técnicos y sociales. Tal integración de especialidades es una sólida base para el éxito de la gestión patrimonial, que ha permitido obtener avances que pueden encajar dentro de los parámetros básicos del modelo de parque patrimonial (ver Tabla 1).

La información recogida en la Tabla 1 permite validar inicialmente la aplicación del modelo de parque patrimonial en el caso peruano y, por qué no, a nivel latinoamericano, lo cual merece un análisis mayor.

Finalmente, cabe destacar la serie de avances aplicativos que ha alcanzado la Comunidad Europea en el reconocimiento de la trascendencia de la gestión del paisaje patrimonial, resaltándose en ello tres consideraciones claves de la CEP (2000): que "todo el territorio es paisaje y no tan sólo los paisajes singulares pintorescos o excepcionales"; "la existencia de un derecho de los ciudadanos a tener y disfrutar de un paisaje de calidad"; y que "el paisaje es un elemento de calidad de vida y un factor de desarrollo de las comunidades" (p. 1). En los casos del Circuito de las Lomas de Lúcumo, Nor Yuyos - Cochas y Salinas - Aguada Blanca, el Colca y Andagua, estas consideraciones relacionadas con el bienestar social-ambiental y el adecuado aprovechamiento productivo del paisaje patrimonial son claramente reconocidas. Mediante dichos ejemplos se demuestra y fortalece la tendencia de no solo considerar el patrimonio paisajístico como un elemento analítico, sino también proyectarlo como un parámetro transversal en la ordenación del territorio y la planificación urbana.

\section{Referencias}

Abad, C., González, J. \& Chamorro, A. (2012). Apu Pariacaca y el Alto Cañete, Estudio de Paisaje Cultural. Programa Qhapaq Ñan. Lima, Perú: Instituto Nacional de Cultura.

Alonso, P. (2014). La transición al pos-productivismo: parques patrimoniales, parques culturales y ordenación territorial. EURE: Revista Latinoamericana de Estudios Urbanos Regionales, 40(119), 217-238. Pontificia Universidad Católica de Chile

Comisión Europea - Comité de Desarrollo Territorial. (1999). Estrategia territorial europea. Hacia un desarrollo equilibrado y sostenible del territorio de la UE. Potsdam, Alemania: Comisión Europea.

Cortes de Aragón. (1997). Ley de Parques Culturales de Aragón. Boletín Oficial, 143(6292), 1-12.

DS-004-2011-VIVIENDA. Reglamento de Acondicionamiento Territorial y Desarrollo Urbano. DS-0042011-VIVIENDA. (2001). Dirección Nacional de Urbanismo, Dirección de Ordenamiento Territorial. Ministerio de Vivienda Construcción y Saneamiento. Lima, Perú.

Folch, R. (2011). Territorio y paisaje en el ámbito mediterráneo. Quaderns de la Mediterranía, Ecología y Cultura, 16(144), 213-217. Barcelona, España: Instituto Europeo del Mediterráneo.

Grupo de Emprendimientos Ambientales, Instituto Nacional de Recursos Naturales. (2007). Documento propuesta: plan de sitio concertado de uso turístico y recreativo del ámbito del camino inca, sector Tanta - San Lorenzo de Quinti RPNYC [sin publicar]. Lima, Perú.

Instituto del Patrimonio Cultural de España, Ministerio de Educación, Cultura y Deporte - Gobierno de España (2007). Plan Nacional de Paisaje Cultural. Recuperado en enero de 2018 de http://www.mecd.gob.es/planes-nacionales/planes-nacionales/paisaje-cultural.html

International Council on Monuments and Sites. (1999). International cultural tourism chárter. Managing Tourism at Places of Heritage Significance. Acuerdos adoptados en la 12ava Asamblea General, México.

Kendall, A., \& Rodríguez, A. (2009). Infraestructura agrícola antigua y su sostenibilidad en la sierra y el altiplano sur. En Desarrolloy perspectivas de los sistemas de andenería de los Andes centrales del Perú (cap. 2, pp. 51-74). Cuzco, Perú: Institut Français d'Études Andines. doi:10.4000/books.ifea.6118

Mata, R. (2006). Un concepto de paisaje para la gestión sostenible del territorio. En R. Mata \& A. Tarroja (Eds.), El paisaje y la gestión del territorio: criterios paisajísticos en la ordenación del territorio y el urbanismo (pp. 17-46). Barcelona, España: Diputación Provincial de Barcelona. 
devenir Vol. 4, N8, JULIO - DICIEMBRE 2017, PP. 134-152 - EstudIOS | ISSN 2312-7562 | E-ISSN 2616-4949

UNIVERSIDAD NACIONAL DE INGENIERÍ, LIMA

Mata, R. (2009). Paisaje y territorio. Un desafío teórico y práctico. Agua, territorio y paisaje: de los instrumentos programados a la planificación aplicada. En L. Sánchez \& M. A. Troitiño (Coord.), V Congreso Internacional de Ordenación del Territorio (243-282). Málaga, España: FUNDICOT.

Mora, J. \& Pimienta, M. (2004). La estrategia territorial europea (ETE): una concepción integradora y cohesionada del espacio. Norba. Revista de Historia, 16(2), 701-707.

Nogué, J. (2006). La producción social y cultural del paisaje. En R. Mata \& A. Tarroja (Eds.), El paisaje y la gestión del territorio: criterios paisajísticos en la ordenación del territorio y el urbanismo (pp. 135-142). España: Diputación Provincial de Barcelona.

Pérez, L. \& Parra, C. (2004). Paisajes culturales: el parque patrimonial como instrumento de revalorización y revitalización del territorio. Theoria, 13(1), 9-24.

Tarroja, A. (2006). Transformaciones territoriales y valoración social del paisaje. En R. Mata \& A. Tarroja (Eds.), El paisaje y la gestión del territorio: criterios paisajísticos en la ordenación del territorio y el urbanismo (pp. 41-50). España: Diputación de Barcelona.

Sabaté, J. (2005). Paisajes culturales, el patrimonio como recurso básico para un nuevo modelo de desarrollo. URBAN, Revista del Departamento de Urbanística y Ordenación del Territorio, o(9), 8-29.

Sabaté, J. (2010). De la preservación del patrimonio a la ordenación del paisaje: intervenciones en paisajes culturales (Europa-Latinoamérica). Labor \& Engenho, 4(1), 10-25.

Servicio Nacional de Áreas Naturales Protegidas \& Ministerio del Ambiente - Intendencia de Áreas Naturales Protegidas. (2016). Plan Maestro 2016-2020 de la Reserva Natural Salinas y Aguada Blanca. Arequipa, Perú: Programa de Acción Nacional para la Lucha contra la Desertificación en el Perú, Cooperación Financiera Alemana.

Servicio Nacional de Áreas Naturales Protegidas, Intendencia de Áreas Naturales Protegidas. (2006). Plan Maestro 2006-2011 de la Reserva Paisajística Nor Yauyos Cochas. Lima, Perú: Programa de Acción Nacional para la Lucha contra la Desertificación en el Perú, Cooperación Financiera Alemana.

Servicio Nacional de Áreas Naturales Protegidas \& Ministerio del Ambiente. (2017). Listado Oficial de Áreas Naturales Protegidas del Estado Peruano. Recuperado en agosto de 2017 de http://www.sernanp.gob.pe/

Organización de Destino del Valle de los Volcanes. (2018). El valle y sus volcanes. Recuperado en enero de 2018 de http://vallevolcanesperu.pe/es/valleyvolcanes/

UNESCO. (2015). Geoparques mundiales. Recuperado en agosto de 2017 de http://www.unesco. org/new/es/office-in-montevideo/ciencias-naturales/earth-sciences/geoparques/

UNESCO - Oficina de Planificación Estratégica/Sección de Cooperación con el Sistema de Naciones Unidas. (2017). La UNESCO Avanza La Agenda 2030 para el Desarrollo Sostenible. París, Francia: UNESCO World Heritage Centre.

UNESCO, Intergovernmental Committee for the Protection of the World Cultural and Natural Heritage. (2016). Operational Guidelines for the Implementation of the World Heritage Convention. París, Francia: UNESCO World Heritage Centre. 